\title{
ANTIOXIDANT PROPERTIES OF SINAPIC ACID: IN VITRO AND IN VIVO APPROACH
}

\author{
NITHYA R, SUBRAMANIAN S* \\ Department of Biochemistry, University of Madras, Guindy Campus, Chennai - 600 025, Tamil Nadu, India. Email: subbus2020@yahoo.co.in \\ Received: 03 March 2017, Revised and Accepted: 27 March 2017
}

\begin{abstract}
Objective: This study was aimed to evaluate the antioxidant potential of sinapic acid in both in vitro and in vivo. Recently, we have reported that oral administration of sinapic acid (3,5-dimethoxy 4-hydroxycinnamic acid) an active phyto ingredient widely distributed in rye, mustard, berries, and vegetables has been shown to ameliorate hyperglycemia.
\end{abstract}

Methods: Experimental Type 2 diabetes was induced in male Wistar rats by feeding high-fat diet to induce insulin resistance followed by intraperitoneal administration of a single low dose streptozotocin ( $35 \mathrm{mg} / \mathrm{kg}$ body weight [bw]). Sinapic acid was administered orally at a concentration of $25 \mathrm{mg} / \mathrm{kg}$ bw/rat/day for 30 days, and its efficacy was compared with metformin. In vitro, antioxidant scavenging properties of sinapic acid were determined using 1,1-diphenyl-2-picrylhydrazyl (DPPH), 2,2'-azino-bis(3-ethylbenzothiazoline-6-sulphonic acid) (ABTS), superoxide, and nitric oxide (NO) assay.

Results: Sinapic acid treatment showed a significant decline in the levels of lipid peroxides, hydroperoxides and protein carbonyls in the plasma and vital tissues of diabetic rats. The treatment also improved the antioxidant status in diabetic rats indicating the antioxidant potential of sinapic acid. In addition, the results of DPPH, ABTS, superoxide, and NO radical scavenging assays substantiate the free radical scavenging efficacy of sinapic acid.

Conclusion: The results of this study evidenced that sinapic acid possess significant antioxidant properties which in turn may be responsible for its antidiabetic properties.

Keywords: Sinapic acid, High-fat diet-streptozotocin, Oxidative stress, Antioxidant, In vitro antioxidant assay.

(C) 2017 The Authors. Published by Innovare Academic Sciences Pvt Ltd. This is an open access article under the CC BY license (http://creativecommons. org/licenses/by/4. 0/) DOI: http://dx.doi.org/10.22159/ajpcr.2017.v10i6.18263

\section{INTRODUCTION}

Chronic hyperglycemia-induced oxidative stress chiefly contributes to the development and progression of diabetes-associated complications. Increased oxidative stress appears to be a deleterious factor accounts for insulin resistance, dyslipidemia, $\beta$-cell dysfunction, impaired glucose tolerance, and ultimately the onset of Type 2 diabetes mellitus (T2DM). Chronic oxidative stress, hyperglycemia, and dyslipidemia are particularly harmful for $\beta$-cells due to low availability of antioxidants, high oxidative energy requirements, decrease in gene expression of key $\beta$-cell genes and early apoptosis. Impairment of $\beta$-cell functioning results in an diminished production of insulin, impairment of glucosestimulated insulin secretion, chronic hyperglycemia and eventually the development of T2DM and its secondary complications [1].

Despite a vast body of research, the molecular mechanisms underlying $\beta$-cell dysfunction and early apoptosis in the pathophysiology of T2DM remain unclear. Experimental and clinical studies suggest that hyperglycemia-induced excessive generation of free radicals chiefly contributes to the development as well as the progression of diabetes mellitus and its secondary complications [2]. Upon exposure to physiological levels of blood glucose, pancreatic $\beta$-cells metabolize glucose normally, during which production of free radicals remains handy. However, in diabetes due to persistent elevation in both fasting and postprandial blood glucose levels, the production of free radicals remains higher, which chiefly contribute to the primary as well as secondary contributions of diabetes mellitus [3,4]. In susceptible individuals, hyperglycemia and hyperlipidemia worsen the $\beta$-cell function by inducing a cascade of processes, respectively, referred to as glucotoxicity and lipotoxicity. Chronic hyperglycemia (glucotoxicity), chronic dyslipidemia (lipotoxicity), or the combination of both (glucolipotoxicity), have been postulated to contribute to the worsening of $\beta$-cell function over time, creating a cruel cycle by which metabolic abnormalities impair insulin secretion, which further aggravates metabolic perturbations in diabetes mellitus $[5,6]$.

Oxidative stress results from an imbalance between radical-generating and radical-scavenging systems that are increased free radical production or reduced activity of antioxidant defenses or both these phenomena. In diabetes, protein glycation and glucose autoxidation may generate excessive free radicals, which in turn catalyze lipid peroxidation [7]. Persistent elevation in glucose levels can stimulate free radical production. Weak defense system of the body becomes unable to respond the enhanced reactive oxygen species (ROS) generation and as a result of an imbalance between ROS and their protection occurs which lead to domination of the oxidative stress [8]. Of course, a certain amount of ROS is necessary for the normal metabolic processes since ROS play various regulatory roles in cells [9]. ROS are produced by neutrophils and macrophages during the process of respiratory burst to eliminate antigens [10]. ROS also serve as stimulating signals of several genes which encode transcription factors, differentiation, and development as well as stimulating cell-cell adhesion, cell signaling, involvement in vasoregulation, fibroblast proliferation, and increased expression of antioxidant enzymes $[11,12]$. However, detonated production of ROS is deleterious. The metabolic abnormalities of diabetes during oxidative stress acts as mediators of insulin resistance and its progression to glucose intolerance and installation of diabetes mellitus.

Antioxidant defense mechanisms include both enzymatic and nonenzymatic strategies. Common antioxidants include the vitamins A, C, E and the tripeptide glutathione, and the enzymes superoxide dismutase (SOD), catalase, glutathione peroxidase (GPx), and glutathione reductase (GR) [13]. Antioxidants not only protect against the direct injurious effects of oxidants but also alter the inflammatory events that play an important role in the pathogenesis of oxidative stress related diseases [14]. 
Type 2 diabetes is strongly associated with obesity and cardiovascular risk. High-fat diet (HFD) fed rats present a metabolic syndrome which is characterized by central obesity, insulin resistance, and hyperglycemia as well as dyslipidemia which is similar to human metabolic syndrome caused by obesity. As the metabolism of carbohydrate and lipid are closely linked processes, derangement in the carbohydrate metabolism may result in dyslipidemia, hence, HFD fed - low dose streptozotocin (STZ) induced model is one of the ideal models for screening of antiobesity activity in diabetic rats. Recent reports on the etiology, epidemiology, and consequences of T2DM necessitate an urgency to find better prognosis, and prevention strategies [15]. Furthermore, STZ damages pancreatic $\beta$-cells, resulting in hypoinsulinemia and chronic hyperglycemia [16].

Various researchers suggest that phytochemicals from traditionally known medicinal plants have been extensively used as an alternative medicine for the management of diabetes [17]. Most of the antidiabetic synthetic drugs in use for long-term therapy have been associated with various toxicities owing to which the developmental process in antidiabetic drug discovery has shifted its focus toward natural plant sources which are having minimal or no side-effects [18]. Some natural products have the ability to lower blood glucose and it should be safer than allopathic drugs if utilization over a prolonged period. Among the natural products, the phenolic compounds are attracting much interest because of their beneficial and pharmacological effects on T2DM and its secondary complications.

Sinapic acid (3,5-dimethoxy 4-hydroxy cinnamic acid) is a naturally occurring carboxylic acid. It is a member of the phenylpropanoid family [19]. It is widely distributed in the plant kingdom and is obtained from various sources such as rye, mustard, berries, and vegetables [20]. Sinapic acid has demonstrated potent antioxidant capacity [21], antiinflammatory [22], anxiolytic [23], peroxynitrite scavenging [24], neuroprotective [25], and antihyperglycemic properties [26]. Serum albumin has been reported to be responsible for the transport of sinapic acid in blood due to its ability to bind with serum albumin through hydrophobic interaction and hydrogen bonding [27,28]. Maximum plasma-sinapic acid level has been described as $40 \mathrm{nM}$ with a bioavailability of $3 \%$ of the total phenolics present in the non-processed cereal meal $[29,30]$. Moreover, the small intestine was reported as the best site for absorption of orally administered sinapic acid through active $\mathrm{Na}^{+}$gradient-driven transport [31]. Plasma sinapic acid level has also been quantified $(1.5 \mu \mathrm{g} / \mathrm{mL})$ after intake of cranberry juice in human using gas chromatography-mass spectrometry [32]. However, metabolism of sinapic acid takes place mainly in the epithelium of the small intestine [33]. Recently, we have evaluated the antidiabetic properties of sinapic acid in HFD-STZ induced Type 2 diabetic rats.

In the absence of systemic reports in literature regarding the antioxidant properties of sinapic acid, the aim of this study is to determine the antioxidant properties of sinapic acid both in vitro and in vivo.

\section{METHODS}

\section{Experimental animals}

Male albino Wistar rats (160-180 g) were purchased from Tamil Nadu Veterinary and Animal Sciences University, Chennai. The rats were housed in polypropylene cages lined with husk. The rats were fed with commercial pellet rats chow (Hindustan Lever Ltd., Bengaluru, India), and had free access to water. Rats were maintained in a controlled environment $\left(12: 12 \mathrm{hrs}\right.$ light/dark cycle and temperature $\left(30 \pm 2^{\circ} \mathrm{C}\right)$. The rats were acclimatized for 1 week before starting the experiments. The experiments were designed and conducted in accordance with the current ethical norms approved by Ministry of Social Justice and Empowerment, Government of India (IAEC No. 05/01/2014).

\section{HFD fed}

The rats were divided into four groups each comprising not less than six rats and allocated into two dietary regimens by feeding either normal or HFD for the initial period of 2 weeks. The ingredients and chemical composition of the HFD were followed as before reported [34]. After 2 weeks of dietary manipulation for the onset of insulin resistance, the groups of rats fed with HFD were injected intraperitoneally with a low dose of STZ (35 mg/kg b.w.) dissolved in freshly prepared $0.1 \mathrm{M}$ cold citrate buffer, $\mathrm{pH}$ 4.5. 1 week after STZ injection, the rats were screened for blood glucose level. Rats are having fasting blood glucose $>250 \mathrm{mg} / \mathrm{dl}$ that exhibited random hyperglycemia and glycosuria were selected for the experiment. The rats were allowed to continue to feed on the respective diets until the end of the experiments.

\section{Experimental design}

The rats were divided into four groups each group comprising six rats.

- Group 1: Control rats

- Group 2: Diabetic rats (HFD-low dose STZ (35 mg/kg body weight [bw])

- $\quad$ Group 3: Diabetic rats treated with sinapic acid (25 mg/kg bw)

- Group4: Diabetic rats treated with metformin (50 mg/kg bw).

Sinapic acid was dissolved in $0.2 \%$ dimethyl sulfoxide and administrated to rats orally using an intragastric tube daily for a period of 30 days.

\section{Sample collection}

After 30 days of the experimental period, the animals were fasted overnight and then sacrificed by cervical decapitation. Blood was collected, and serum was separated by centrifugation. The pancreas, liver, and kidney were carefully removed, weighed and washed in icecold saline. The tissues were sliced into pieces and homogenized in an appropriate buffer ( $\mathrm{pH}$ 7.0). The homogenates were centrifuged at $3000 \mathrm{rpm}$ for $10 \mathrm{~min}$ at $0^{\circ} \mathrm{C}$ in cold centrifuge. The supernatant was separated and used for various biochemical estimations.

\section{Assay of antioxidant status}

\section{In vitro antioxidant assays}

\section{1,1-diphenyl-2-picrylhydrazyl (DPPH) assay}

The DPPH radical scavenging activity of sinapic acid was determined by the method of Brand-Williams et al. with some modifications [35]. The methanolic solution of DPPH $(60 \mu \mathrm{M})$ was mixed with an equivalent aliquot of different concentration (3.125-100 $\mu \mathrm{M})$ of sinapic acid in methanol. The absorbance was determined at $515 \mathrm{~nm}$ after 2 minutes incubation in the dark, spectrophotometrically.

2,2'-azino-bis(3-ethylbenzothiazoline-6-sulphonic acid) (ABTS) assay ABTS radical scavenging activity of sinapic acid was determined according to the method of Re et al., (1999) [36]. Briefly, ABTS radical cation was produced by mixing ABTS stock solution ( $7 \mathrm{mM}$ in water) with $2.45 \mathrm{mM}$ potassium persulfate and allowing the mixture to stand in the dark at room temperature for 12-16 hrs before use. Then, ABTS radical solution was diluted with ethanol to an absorbance of 0.7 at $734 \mathrm{~nm}$. To $3.0 \mathrm{ml}$ of diluted ABTS radical solution, $30 \mu \mathrm{l}$ of different concentration (3.125-100 $\mu \mathrm{M}$ ) of sinapic acid in ethanol was added and after 1 minute, the decrease in absorbance was measured at $734 \mathrm{~nm}$ spectrophotometrically.

\section{Superoxide anion radical scavenging assay}

The superoxide radical scavenging activity of sinapic acid was measured by the method of Fontana et al., (2001) [37]. In this method, the activity is measured by reduction of riboflavin/light/nitro blue tetrazolium (NBT). The $1 \mathrm{ml}$ of reaction mixture contained phosphate buffer, nicotinamide adenine dinucleotide (NADH), NBT and various concentrations of the sample solution. The method is based on the generation of superoxide radical by autoxidation of riboflavin in the presence of light. The superoxide radical reduces NBT to a blue colored formazan that can be measured at $560 \mathrm{~nm}$.

Assay for nitric oxide (NO) scavenging activity Sodium nitroprusside $(5 \mathrm{mM})$ in phosphate buffer with $\mathrm{pH} 7.7$ was incubated with 3.125-100 $\mu \mathrm{M}$ concentrations of drug dissolved in a suitable solvent (alcohol), and tubes were incubated at $25^{\circ} \mathrm{C}$ for 120 minutes. At intervals, $0.5 \mathrm{ml}$ of incubation solution was 
removed and diluted with $0.5 \mathrm{ml}$ of Griess reagent. The absorbance of the chromophore formed during diazotization of nitrite with sulphanilamide and subsequent $\mathrm{N}$-naphthyl ethylenediamine was measured at $546 \mathrm{~nm}[38]$.

\section{In vivo antioxidant assay}

\section{Assay of antioxidant status}

The levels of lipid peroxides and hydroperoxides were determined in plasma and tissue homogenates [39-41]. The activities of enzymatic antioxidants such as SOD [42], catalase [43], GPx [44], glutathioneS-transferase (GST) [45], and GR [46] were assayed in the tissue homogenates of control and experimental groups of rats. The levels of non-enzymatic antioxidants such as vitamin C, vitamin E, ceruloplasmin, and glutathione (GSH) were also determined [47-50].

\section{Statistical analysis}

The results were expressed as mean \pm standard error of mean of six rats per group, and statistical significance was evaluated by one-way analysis of variance using SPSS (version 16) program followed by the least significant difference. Values were considered statistically significant when $\mathrm{p}<0.05$.

\section{RESULTS}

Figs. 1 and 2 depict the dose-dependent effect of sinapic acid on the percentage inhibition of DPPH and ABTS radicals present in the reaction mixtures. Sinapic acid scavenges both DPPH and ABTS radicals in a concentration-dependent manner. However, at a concentration of $100 \mu \mathrm{g} / \mathrm{ml}$, sinapic acid significantly scavenged $82 \%$ of DPPH and $86.5 \%$ ABTS radicals. Superoxide and NO scavenging potential of the sinapic acid are presented in Figs. 3 and 4, respectively. Sinapic acid

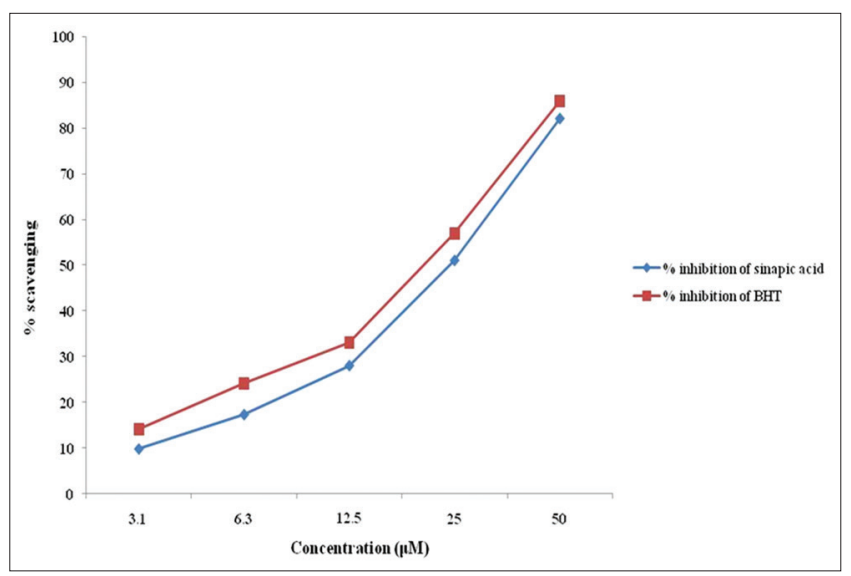

Fig. 1: In vitro 1,1-diphenyl-2-picrylhydrazyl radical scavenging effect of sinapic acid

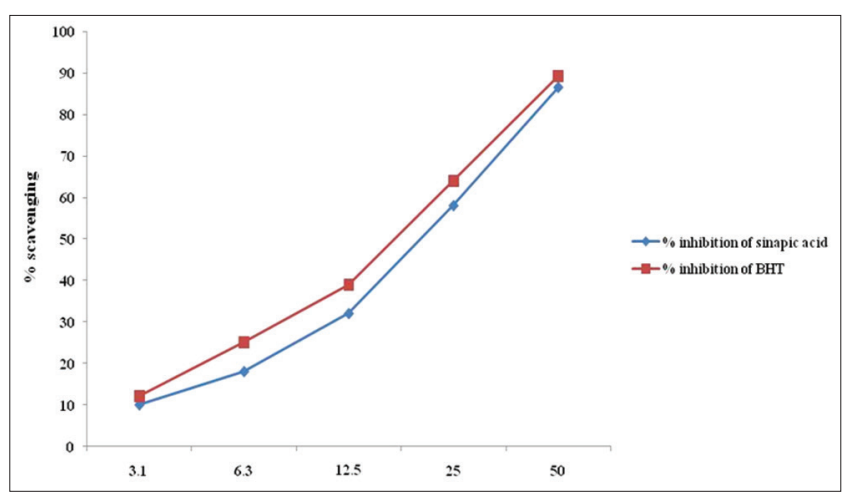

Fig. 2: 2,2'-azino-bis(3-ethylbenzothiazoline-6-sulphonic acid) radical scavenging effect of sinapic acid exhibited a maximum of $88.6 \%$ superoxide scavenging activity and $78 \%$ NO scavenging potential.

Tables 1-4 exemplify the levels of TBARS, hydroperoxides and protein carbonyls in plasma, pancreatic, hepatic and renal tissues of control and experimental groups of rats. The significant $(p<0.05)$ increase noted on the levels of these oxidative stress markers in plasma as well as in the tissues of diabetic group of rats were declined $(\mathrm{p}<0.05)$ significantly to near normalcy by sinapic acid as well as metformin treatment to diabetic groups of rats.

The activities of enzymatic antioxidants such as SOD, CAT, GPx and GST (Tables 5-7) in the pancreatic, hepatic, and renal tissues were significantly improved in sinapic acid treated diabetic rats indicating the antioxidant potential of sinapic acid. Furthermore, the plasma levels of non-enzymatic antioxidants such as vitamin C, vitamin E, reduced glutathione and ceruloplasmin (Table 8), and hepatic as well as renal GSH (Table 9) content were found to be increased on oral treatment with sinapic acid.

\section{DISCUSSION}

Antioxidants derived from medicinal plants provide protection to cells by scavenging the excessive free radicals through offsetting ROS. This has been made possible due to the presence of certain bioactive substances, such as phenolic compounds, flavonoids and essential oils, and rendering plants with antioxidant activity [51].

\section{In vitro antioxidant potential}

The DPPH and ABTS radicals scavenging activity of sinapic acid is depicted in Figs. 1 and 2, respectively. DPPH radical scavenging activity was quantified in terms of percentage inhibition of a pre-formed free radical by antioxidants. There was a significant improvement in the percentage inhibition of the DPPH radicals

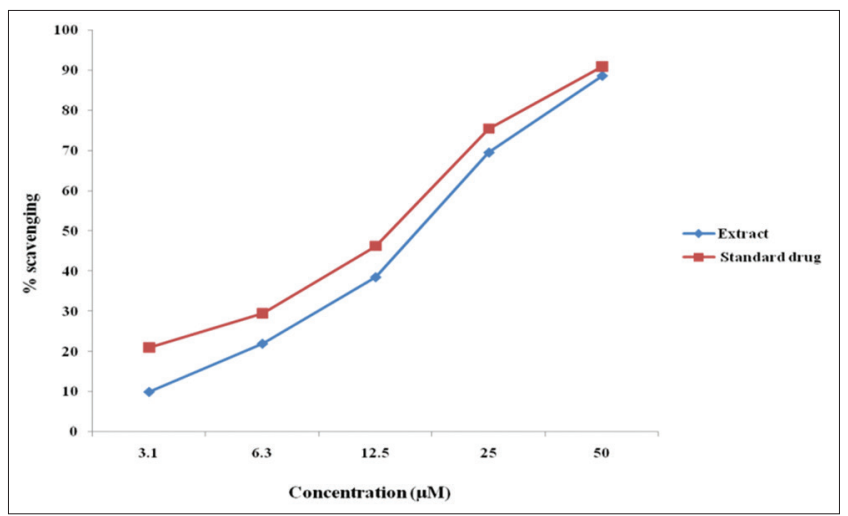

Fig. 3: Superoxide radical scavenging effect of sinapic acid

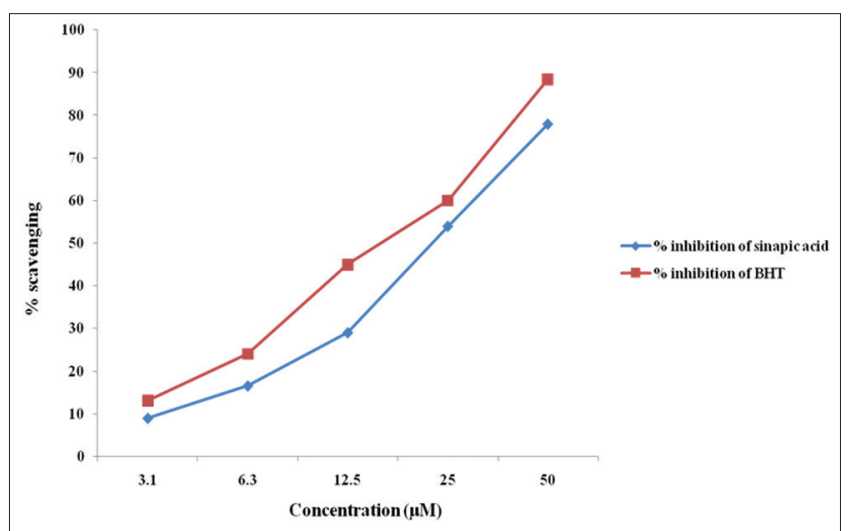

Fig. 4: Nitric oxide radical scavenging effect of sinapic acid 
Table 1: The levels of lipid peroxides, hydroperoxides and protein carbonyls in plasma of control and experimental groups of rats after 30 days of experimental period

\begin{tabular}{lll}
\hline Groups & Lipid peroxides & Hydroperoxides \\
\hline Control & $3.60 \pm 0.22$ & $9.9 \pm 0.50$ \\
Diabetic control & $10.2 \pm 0.33^{\mathrm{a} *}$ & $27.30 \pm 2.15^{\mathrm{a} *}$ \\
Diabetic+sinapic acid & $4.45 \pm 0.28^{\mathrm{ab} * \mathrm{c}}$ & $17.80 \pm 1.50^{\mathrm{a} \mathrm{b} * \mathrm{c}}$ \\
Diabetic+metformin & $4.61 \pm 0.25^{\mathrm{a} \# \mathrm{~b} *}$ & $15.61 \pm 1.12^{\mathrm{a} * \mathrm{~b} \#}$ \\
\hline
\end{tabular}

Units are expressed as $\mathrm{nM} / \mathrm{ml}$ for lipid peroxides; $10^{-5} \mathrm{mM} / \mathrm{dl}$ for hydroperoxides; $\mathrm{nM} / \mathrm{mg}$ of protein for protein carbonyls. Values are given as mean \pm SEM for groups of six rats in each. One-way ANOVA followed by post hoc test LSD. Statistical significance was compared within the groups as follows: ${ }^{\mathrm{a} C o n t r o l ~ r a t s ; ~}{ }^{\mathrm{b}} \mathrm{Diabetic}$ control rats;

${ }^{c}$ Diabetic rats treated with metformin. Values are statistically significant at ${ }^{\circledR} \mathrm{p}<0.05 ;{ }^{\#} \mathrm{p}<0.01 ;{ }^{*} \mathrm{p}<0.001$. SEM: Standard error of mean, LSD: Least square difference

Table 2: Effect of sinapic acid treatment on the levels of lipid peroxides, hydroperoxides, and protein carbonyls in pancreatic tissues of experimental groups of rats

\begin{tabular}{|c|c|c|c|}
\hline Groups & Lipid peroxides & Hydroperoxides & Protein carbonyls \\
\hline Control & $37.33 \pm 2.40$ & $14.10 \pm 0.88$ & $5.18 \pm 0.25$ \\
\hline Diabetic control & $65.21 \pm 4.33^{\mathrm{a} *}$ & $32.04 \pm 1.71^{\mathrm{a} *}$ & $20.10 \pm 1.13^{\mathrm{a} *}$ \\
\hline Diabetic+sinapic acid & $40.00 \pm 2.40^{\mathrm{ab} * \mathrm{c}}$ & $17.32 \pm 1.15^{\mathrm{ab} * \mathrm{c}}$ & $11.21 \pm 0.58^{\mathrm{a} * \mathrm{~b} * \mathrm{c}}$ \\
\hline Diabetic+metformin & $38.30 \pm 3.00^{\mathrm{a} @ \mathrm{~b} *}$ & $15.02 \pm 0.71^{\mathrm{ab} *}$ & $10.88 \pm 0.62^{\mathrm{a} * \mathrm{~b} *}$ \\
\hline
\end{tabular}

Units are expressed as $\mathrm{mM} / 100 \mathrm{~g}$ of wet tissue for lipid peroxides and hydroperoxides; $\mathrm{nM} / \mathrm{mg}$ of protein for protein carbonyls. Values are given as mean \pm SEM for groups of six rats in each. One-way ANOVA followed by post hoc test LSD. Statistical significance was compared within the groups as follows: ${ }^{a}$ Control rats; ${ }^{b}$ Diabetic control rats; ${ }^{c}$ Diabetic rats treated with metformin. Values are statistically significant at ${ }^{\circledR} p<0.05$; ${ }^{\#} p<0.01$; ${ }^{*} p<0.001$. SEM: Standard error of mean, LSD: Least square difference

Table 3: Effect of sinapic acid treatment on the levels of lipid peroxides, hydroperoxides, and protein carbonyls in hepatic tissues of control and experimental groups of rats

\begin{tabular}{lll}
\hline Groups & Lipid peroxides & Hydroperoxides \\
\hline Control & $1.37 \pm 0.12$ & $47.42 \pm 4.09$ \\
Diabetic control & $4.41 \pm 0.25^{\mathrm{a} *}$ & $127.10 \pm 7.03^{\mathrm{a} *}$ \\
Diabetic+sinapic acid & $2.36 \pm 0.17^{\mathrm{a} * \mathrm{~b} * \mathrm{c}}$ & $81.74 \pm 4.02^{\mathrm{a} * \mathrm{~b} * \mathrm{c}}$ \\
Diabetic+metformin & $2.88 \pm 0.21^{\mathrm{a} * \mathrm{~b} *}$ & $71.41 \pm 3.12^{\mathrm{a} * \mathrm{~b} *}$ \\
\hline
\end{tabular}

Units are expressed as $\mathrm{mM} / 100 \mathrm{~g}$ of wet tissue for lipid peroxides and hydroperoxides; $\mathrm{nM} / \mathrm{mg}$ of protein for protein carbonyls. Values are given as mean \pm SEM for

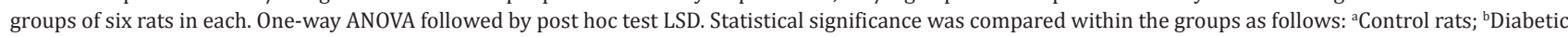
control rats; ' Diabetic rats treated with metformin. Values are statistically significant at ${ }^{\circledR} \mathrm{p}<0.05$; ${ }^{*} \mathrm{p}<0.01$; ${ }^{*} \mathrm{p}<0.001$. SEM: Standard error of mean, LSD: Least square difference

Table 4: Effect of sinapic acid treatment on the levels of lipid peroxides, hydroperoxides, and protein carbonyls in renal tissues of control and experimental groups of rats

\begin{tabular}{|c|c|c|c|}
\hline Groups & Lipid peroxides & Hydroperoxides & Protein carbonyls \\
\hline Control & $1.05 \pm 0.073$ & $50.10 \pm 3.18$ & $3.75 \pm 0.30$ \\
\hline Diabetic control & $3.40 \pm 0.20^{\mathrm{a} *}$ & $85.50 \pm 3.80^{\mathrm{a} *}$ & $17.47 \pm 0.89^{a *}$ \\
\hline Diabetic + sinapic acid & $2.18 \pm 0.13^{\mathrm{a} * \mathrm{~b} * \mathrm{c}}$ & $59.28 \pm 3.58^{\mathrm{ab} * \mathrm{c}}$ & $9.11 \pm 0.55^{\mathrm{a} * \mathrm{~b} *}$ \\
\hline Diabetic+metformin & $1.98 \pm 0.12^{\mathrm{a} * \mathrm{~b} *}$ & $60.11 \pm 4.40^{\mathrm{ab} *}$ & $7.24 \pm 0.48^{\mathrm{a} * \mathrm{~b} * c @}$ \\
\hline
\end{tabular}

Units are expressed as mM/100 g of wet tissue for lipid peroxides and hydroperoxides; $\mathrm{nM} / \mathrm{mg}$ of protein for protein carbonyls. Values are given as mean \pm SEM for groups of six rats in each. One-way ANOVA followed by post hoc test LSD. Statistical significance was compared within the groups as follows: ${ }^{a}$ Control rats; ${ }^{b}$ Diabetic control rats; ' Diabetic rats treated with metformin. Values are statistically significant at ${ }^{@} \mathrm{p}<0.05$; ${ }^{\mathrm{p}} \mathrm{p}<0.01$; ${ }^{*} \mathrm{p}<0.001$. SEM: Standard error of mean, LSD: Least square difference

Table 5: Activities of SOD, CAT, GPx, and GST in pancreatic tissues of control and experimental groups of rats.

\begin{tabular}{|c|c|c|c|c|}
\hline Groups & SOD & CAT & GPx & GST \\
\hline Control & $5.57 \pm 0.32$ & $25.00 \pm 2.20$ & $6.81 \pm 0.31$ & $5.91 \pm 0.29$ \\
\hline Diabetic & $3.20 \pm 0.22^{a *}$ & $6.63 \pm 0.42^{\mathrm{a} *}$ & $3.10 \pm 0.24^{\mathrm{a} *}$ & $2.00 \pm 0.31^{\mathrm{a} *}$ \\
\hline Diabetic+sinapic acid & $4.44 \pm 0.20^{\mathrm{a} * \mathrm{~b} * \mathrm{c}}$ & $13.40 \pm 0.69^{a * b \# c}$ & $5.59 \pm 0.34^{\mathrm{a} @ \mathrm{~b} * \mathrm{c}}$ & $4.50 \pm 0.24^{\mathrm{a} * \mathrm{~b} * \mathrm{c}}$ \\
\hline Diabetic+metformin & $4.91 \pm 0.33^{\mathrm{a} * \mathrm{~b} *}$ & $15.42 \pm 0.73^{\mathrm{a} * \mathrm{~b} \#}$ & $6.13 \pm 0.34^{\mathrm{ab} *}$ & $4.99 \pm 0.31^{\mathrm{a} * \mathrm{~b} *}$ \\
\hline
\end{tabular}

Activities of enzymes are expressed as $50 \%$ of inhibition of epinephrine autoxidation/min for SOD; $\mathrm{mM}$ of hydrogen peroxide decomposed/min/mg of protein for catalase; $\mathrm{mM}$ of glutathione oxidized $/ \mathrm{min} / \mathrm{mg}$ of protein for $\mathrm{GPx} ; \mathrm{U} / \mathrm{min} / \mathrm{mg}$ of protein for GST. Values are given as mean \pm SEM for groups of six rats in each. One-way ANOVA followed by post-hoc test LSD. Statistical significance was compared within the groups as follows: ${ }^{\text {aCh }}$ trol rats; ${ }^{b}$ Diabetic control rats; ${ }^{c}$ Diabetic rats treated with metformin. Values are statistically significant at ${ }^{@} \mathrm{p}<0.05$; ${ }^{*} \mathrm{p}<0.01 ;{ }^{*} \mathrm{p}<0.001$. SOD: Superoxide dismutase, CAT: Catalase, GPx: Glutathione peroxidase, GST: Glutathione-S-transferase

by sinapic acid. ABTS radical activity was quantified in terms of percentage inhibition of the ABTS radical cation by antioxidants in each sample sinapic acid showed $82 \%$ inhibition at a concentration of $50 \mu \mathrm{M}$ in DPPH assay and $86.5 \%$ inhibition at a concentration of $50 \mu \mathrm{M}$ in ABTS radical assay reflecting its radical scavenging capacity. 
Table 6: Activities of SOD, CAT, GPx, GST, and GR in hepatic tissues of control and experimental groups of rats

\begin{tabular}{|c|c|c|c|c|c|}
\hline Groups & SOD & CAT & GPx & GST & GR \\
\hline Control & $11.55 \pm 0.62$ & $80.10 \pm 3.11$ & $10.52 \pm 0.49$ & $8.09 \pm 0.46$ & $28.30 \pm 2.74$ \\
\hline Diabetic & $4.65 \pm 0.23^{\mathrm{a} *}$ & $38.50 \pm 2.48^{\mathrm{a} *}$ & $4.68 \pm 0.18^{\mathrm{a} *}$ & $3.60 \pm 0.18^{\mathrm{a} *}$ & $12.60 \pm 0.68^{\mathrm{a} *}$ \\
\hline Diabetic + sinapic acid & $7.82 \pm 0.24^{\mathrm{a} * \mathrm{~b} * \mathrm{c}}$ & $67.10 \pm 2.44^{\mathrm{a} \# \mathrm{~b} * \mathrm{c}}$ & $7.20 \pm 0.36^{\mathrm{a} * \mathrm{~b} * \mathrm{c}}$ & $6.43 \pm 0.28^{\mathrm{a} \# \mathrm{~b} * \mathrm{c}}$ & $22.33 \pm 1.75^{\mathrm{a} @ \mathrm{~b} \# \mathrm{c}}$ \\
\hline Diabetic+metformin & $7.20 \pm 0.27^{\mathrm{a} * \mathrm{~b} *}$ & $70.81 \pm 3.05^{\mathrm{a} * \mathrm{~b} *}$ & $8.00 \pm 0.23^{\mathrm{a} * \mathrm{~b} *}$ & $7.00 \pm 0.29^{\mathrm{a} \# \mathrm{~b} *}$ & $23.50 \pm 2.00^{\mathrm{ab} *}$ \\
\hline
\end{tabular}

Activities of enzymes are expressed as $50 \%$ of inhibition of epinephrine autoxidation/min for SOD; $\mathrm{mM}$ of hydrogen peroxide decomposed/min/mg of protein for catalase; $\mathrm{mM}$ of glutathione oxidized/min/mg of protein for GPx; U/min/mg of protein for GST; $\mu$ M of DTNB-GSH conjugate formed/min/mg of protein for GR. Values are given as mean \pm SEM for groups of six rats in each. One-way ANOVA followed by post-hoc test LSD. Statistical significance was compared within the groups as follows: ${ }^{a}$ Control rats; ${ }^{b}$ Diabetic control rats; 'Diabetic rats treated with metformin. Values are statistically significant at ${ }^{\circledR} \mathrm{p}<0.05 ;{ }^{\#} \mathrm{p}<0.01 ;{ }^{*} \mathrm{p}<0.001$. GR: Glutathione reductase

Table 7: Activities of SOD, CAT, GPx, GST, and GR in renal tissues of control and experimental groups of rats

\begin{tabular}{|c|c|c|c|c|c|}
\hline Groups & SOD & Catalase & GPx & GST & GR \\
\hline Control & $17.20 \pm 0.93$ & $44.34 \pm 3.01$ & $8.0 \pm 0.24$ & $6.40 \pm 0.16$ & $33.11 \pm 2.00$ \\
\hline Diabetic & $8.23 \pm 0.51^{\mathrm{a} *}$ & $17.10 \pm 1.11^{\mathrm{a} *}$ & $3.66 \pm 0.21^{\mathrm{a} *}$ & $2.42 \pm 0.16^{\mathrm{a} *}$ & $11.40 \pm 0.72^{\mathrm{a} *}$ \\
\hline Diabetic+sinapic acid & $14.08 \pm 0.58^{\mathrm{a} @ \mathrm{~b} * \mathrm{c}}$ & $29.01 \pm 1.74^{\mathrm{a} * \mathrm{~b} * \mathrm{c}}$ & $6.50 \pm 0.23^{\mathrm{a} * \mathrm{~b} * \mathrm{c}}$ & $4.32 \pm 0.25^{\mathrm{a} * \mathrm{~b} * \mathrm{c}}$ & $26.51 \pm 1.78^{\mathrm{a} @ \mathrm{~b} * c}$ \\
\hline Diabetic+metformin & $13.39 \pm 0.45^{\mathrm{a} \mathrm{b} *}$ & $30.64 \pm 2.27^{\mathrm{a} * \mathrm{~b} \#}$ & $7.10 \pm 0.21^{\mathrm{a} * \mathrm{~b} *}$ & $5.01 \pm 0.30^{\mathrm{a} * \mathrm{~b} *}$ & $27.55 \pm 1.31^{\mathrm{a} * \mathrm{~b} *}$ \\
\hline
\end{tabular}

Activities of enzymes are expressed as: $50 \%$ of inhibition of epinephrine autoxidation/min for SOD; mM of hydrogen peroxide decomposed/min/mg of protein for catalase; $\mathrm{mM}$ of glutathione oxidized/min/mg of protein for GPx; U/min/mg of protein for GST; $\mu$ M of DTNB-GSH conjugate formed/min/mg of protein for GR. Values are given as mean \pm SEM for groups of six rats in each. One-way ANOVA followed by post-hoc test LSD. Statistical significance was compared within the groups as follows: ${ }^{\mathrm{a} C o n t r o l ~ r a t s ; ~}{ }^{\mathrm{b}}$ Diabetic control rats; ${ }^{\mathrm{c} D i a b e t i c ~ r a t s ~ t r e a t e d ~ w i t h ~ m e t f o r m i n . ~ V a l u e s ~ a r e ~ s t a t i s t i c a l l y ~ s i g n i f i c a n t ~ a t ~}{ }^{@} \mathrm{p}<0.05 ;{ }^{\#} \mathrm{p}<0.01 ;{ }^{*} \mathrm{p}<0.001$

Table 8: Effect of sinapic acid on the levels of vitamin E, vitamin C, ceruloplasmin, and reduced glutathione in plasma of control and experimental groups of rats

\begin{tabular}{llll}
\hline Groups & Vitamin E & Vitamin C & Ceruloplasmin \\
\hline Control & $1.00 \pm 0.06$ & $1.53 \pm 0.080$ & $14.00 \pm 0.13$ \\
Diabetic & $0.40 \pm 0.031^{\mathrm{a} *}$ & $0.46 \pm 0.048^{\mathrm{a} *}$ & $3.00 \pm 0.32^{\mathrm{a} *}$ \\
Diabetic+sinapic acid & $0.81 \pm 0.052^{\mathrm{ab} * \mathrm{c}}$ & $0.94 \pm 0.073^{\mathrm{a} * \mathrm{~b} * \mathrm{c}}$ & $10.11 \pm 0.56^{\mathrm{a} * \mathrm{~b} * \mathrm{c}}$ \\
Diabetic+metformin & $0.86 \pm 0.04^{\mathrm{a} * \mathrm{~b} \#}$ & $1.00 \pm 0.043^{\mathrm{a} * \mathrm{~b} \#}$ & $11.00 \pm 1.12^{\mathrm{a} *}$ \\
\hline
\end{tabular}

Units: $\mathrm{mg} / \mathrm{dl}$. Values are given as mean \pm SEM for groups of six rats in each. One-way ANOVA followed by post-hoc test LSD. Statistical significance was compared within the groups as follows: ${ }^{a}$ Control rats; ${ }^{b}$ Diabetic control rats; ${ }^{\mathrm{c}}$ Diabetic rats treated with metformin. Values are statistically significant at ${ }^{@} \mathrm{p}<0.05$; ${ }^{\#} \mathrm{p}<0.01$; ${ }^{*} \mathrm{p}<0.001$

Table 9: Effect of sinapic acid on the level of reduced glutathione in pancreas, liver, and kidney tissues of control and experimental groups of rats

\begin{tabular}{lll}
\hline \multirow{2}{*}{ Groups } & Reduced glutathione & \\
\cline { 2 - 3 } & Pancreas & Liver \\
\hline Control & $22.44 \pm 1.22$ & $48.10 \pm 2.67$ \\
Kiabetic & $9.04 \pm 0.42^{\mathrm{a} *}$ & $23.41 \pm 1.19^{\mathrm{a} *}$ \\
Diabetic+sinapic acid & $14.92 \pm 0.42 \mathrm{a}^{* \mathrm{~b} * \mathrm{c}}$ & $38.30 \pm 2.70^{\mathrm{a} \mathrm{b} * \mathrm{c}}$ \\
Diabetic+metformin & $17.00 \pm 0.99^{\mathrm{a} * \mathrm{~b} *}$ & $21.03 \pm 0.78^{\mathrm{a} *}$ \\
\hline
\end{tabular}

Units: $\mathrm{mg} / 100 \mathrm{~g}$ of wet tissue. Values are given as mean \pm S.E.M for groups of six rats in each. One-way ANOVA followed by post-hoc test LSD. Statistical significance was compared within the groups as follows: ${ }^{\mathrm{a} C o n t r o l ~ r a t s ; ~}{ }^{\mathrm{b}}$ Diabetic control rats; ${ }^{\mathrm{c} D i a b e t i c}$ rats treated with metformin. Values are statistically significant at ${ }^{@} \mathrm{p}<0.05 ;{ }^{\#} \mathrm{p}<0.01 ;{ }^{*} \mathrm{p}<0.001$

Among, the several in vitro antioxidant assays, DPPH and ABTS radical assay have been widely used as more convenient methods in determining the free radical scavenging efficacy of the lead molecules [52,53]. The antiradical activity assay is based on the reduction of DPPH in methanolic solution. Due to the presence of an odd electron, DPPH gives a strong absorption maximum at $517 \mathrm{~nm}$. As this electron becomes paired off in the presence of a hydrogen donor, i.e., a free radical scavenging antioxidant, the absorption strength is decreased, and the resulting decolorization is stoichiometric with respect to the number of electrons captured.

ABTS radicals are more reactive than DPPH radicals and the reaction with ABTS radicals involve a single electron transfer process. The principle lying behind the ABTS radical assay is the pre-formed radical monocation of ABTS radical which is generated by oxidation of ABTSradicals with potassium persulfate and is reduced in the presence of such hydrogen-donating antioxidants. The antioxidant activity of different flavonoids depends on the number and location of hydroxyl groups of the flavonoid ring system [54]. Sinapic acid showed $86.5 \%$ inhibition at a concentration of $50 \mu \mathrm{M}$ in ABTS radical assay which exemplifies its significant radical scavenging capacity. The results of DPPH and ABTS radical scavenging assay imply the free radical scavenging property of sinapic acid which was comparable with the efficacy of metformin.

The primary free radical in most biological systems is superoxide $\left(\mathrm{O}^{2 \bullet-}\right)$. Although $\mathrm{O}^{2 \bullet-}$ itself is quite uncreative compared to the other radicals, it can be decomposed to form stronger oxidative species such as singlet oxygen and hydroxyl radicals. From the investigations, it was found that sinapic acid scavenged $\mathrm{O}^{2 \cdot-}$ significantly and in a concentrationdependent manner. The $\mathrm{O}^{2 \cdot-}$ scavenging activity was determined by phenazine methosulfate/NADH-NBT system wherein $\mathrm{O}^{2-\text { - }}$ derived from dissolved oxygen by phenazine methosulfate/NADH coupling reaction reduces NBT. The decrease in absorbance at $560 \mathrm{~nm}$ with antioxidants thus indicates the consumption of superoxide anions in the reaction mixture. Sinapic acid exhibited a maximum of $88.6 \%$ superoxide 
scavenging activity (Fig. 3) with a significant extent at a concentration of $50 \mu \mathrm{M}$. Sinapic acid at a concentration of $50 \mu \mathrm{M}$ also quenched $78 \%$ NO radical (Fig. 4).

NO acts as neurotransmitter through exerting its effect on different body operations, such as neurotransmission, synaptic plasticity, vasodilation, and CNS memory $[55,56]$. Besides key role of NO in facilitating normal function, it has been observed that NO has been associated with pathophysiological states such as neurodegenerative and Alzheimer's disease. Excessive release of NO in the body can cause DNA fragmentation, cell damage and neuronal cell death [57]. Phytochemicals can play a crucial role in reducing the amount of NO through their efficient $\mathrm{NO}$ scavenging activity.

Kikuzaki et al. [21] have reported that sinapic acid possess significant inhibitory activity of $33.2 \%$ of the DPPH radical at the concentration of $20 \mu \mathrm{M}$. A 0.5 molar ratio of sinapic acid inhibits $88.4 \%$ of the DPPH radical [58]. According to Hotta et al., [59] the concentration of sinapic acid that reduced $50 \%$ of DPPH radical concentration inhibitory concentration $50 \%$ was $0.3 \mathrm{mM}$ for sinapic acid. Sinapic acid has $55.42 \%$ of ABTS radical inhibiting activity at the concentration of 10-50 $\mu \mathrm{M}$. Superoxide radical scavenging activity inhibition was $35.52 \%$ using $0.05 \mathrm{mM}$ of sinapic acid [60]. Masek et al. [61] have reported that sinapic acid showed $39.4 \%$ inhibition activity at $5-30 \mu \mathrm{g} / \mathrm{ml}$. Thus, the results of this study are on par with the earlier reports indicating that sinapic acid effectively scavenges the free radicals.

\section{In vivo antioxidant potential}

Persistent hyperglycemia results in the increased formation of advanced glycation end and lipid peroxidation products that exacerbate intracellular oxidative stress, resulting in a loss of molecular integrity, disruption in cellular signaling and homeostasis, followed by inflammation and tissue injury. Having evolved in an oxygen environment, most cells, including pancreatic $\beta$-cells, have acquired intricate mechanisms to defend against ROS toxicity. Antioxidants are considered important nutraceuticals on account of their many health benefits and widely used in the food industry as potential inhibitors of lipid peroxidation. It is generally accepted that the consumption of plant foods is associated with a lower risk of development of oxidative stress-mediated diseases [62]. Polyphenols represent one of the largest chemical entities in the plant kingdom, gathered into four main classes such as phenolic acids, flavonoids, stilbenes, and lignans [63]. In recent times, polyphenolic compounds have attracted great attention and have been subject to broad research primarily because of their antioxidant properties and beneficial health effects resulting from them [64].

Oxidative stress is associated with oxidative modification of biomolecules which are involved in a number of pathophysiological processes such as aging, diabetes, atherosclerosis, inflammation, and carcinogenesis. Lipid peroxidation is a free radical process involving a source of secondary free radical, which further can act as the second messenger or can directly react with other biomolecules, enhancing biochemical lesions. Lipid peroxidation primarily occurs on polyunsaturated fatty acids located on the cell membranes and it further proceeds with a radical chain reaction. Hydroxyl radical is thought to initiate ROS and remove hydrogen atom, thus producing lipid radical and further converted into diene conjugate. Further, by the addition of oxygen, it forms peroxyl radical; this highly reactive radical attacks another fatty acid forming lipid hydroperoxide ( $\mathrm{LOOH}$ ) and a new radical. Thus, lipid peroxidation is propagated. Due to lipid peroxidation, a number of compounds such as alkanes, malanoaldehyde, and isoprotanes are formed. These compounds are used as markers in lipid peroxidation assay and have been verified in many diseases such as neurogenerative diseases, ischemic reperfusion injury, and diabetes.

The elevated cytotoxic and highly reactive oxidative stress markers such as lipid peroxides and hydroperoxides causes oxidative damage to proteins as well as DNA and the reduced cellular non-enzymatic and enzymatic antioxidant levels in diabetic conditions further increases the severity of tissue dysfunction resulting in decreased insulin synthesis, secretion and finally resulting in $\beta$-cell death. In this study, the elevated levels of lipid peroxides and hydroperoxides in plasma, pancreatic, hepatic, and renal tissues of diabetic rats were significantly altered on oral administration of sinapic acid which demonstrates the anti-lipid peroxidative property of sinapic acid under oxidative stress environment.

Cells are protected against oxidative stress by an interacting network of antioxidant enzymes [65]. Superoxide released by processes such as oxidative phosphorylation is converted to hydrogen peroxide and further reduced to water. This detoxification pathway is the result of multiple enzymes, with SODs catalyzing the first step and then catalases and various peroxidases removing hydrogen peroxide [66].

SODs are a class of closely related enzymes that catalyze the breakdown of superoxide anion into oxygen and hydrogen peroxide [67]. SOD enzymes are present in almost all aerobic cells and in extracellular fluids [68]. Catalase is a common enzyme found in nearly all living organisms, which are exposed to oxygen, where it functions to catalyze the decomposition of hydrogen peroxide to water and oxygen [69]. Hydrogen peroxide is a harmful by-product of many normal metabolic processes: To prevent damage, it must be quickly converted into other less dangerous substances. To this end, catalase is frequently used by cells to rapidly catalyze the decomposition of hydrogen peroxide into less reactive gaseous oxygen and water molecules [70]

The glutathione system includes glutathione, GR, GPx, and GST. This system is found in animals, plants, and microorganisms [71]. GPX is an enzyme containing four selenium-cofactors that catalyze the breakdown of hydrogen peroxide and organic hydroperoxides. There are at least four different GPx isozymes in animals [72]. The GSTs show high activity with lipid peroxides. These enzymes are at particularly high levels in the liver and also serve in detoxification metabolism [73]. The activities of enzymatic antioxidants such as SOD, CAT, GPx, and GST in the pancreatic, hepatic and renal tissues were significantly improved in sinapic acid treated diabetic rats indicating the antioxidant potential of sinapic acid.

Reduced glutathione, a ubiquitous tripeptide thiol, is an important intracellular metabolite. It acts as an antioxidant and provides secondary line of defense against intracellular free radicals and peroxides generated by oxidative stress. Reduced state of the cell is maintained by high level of GSH/GSSG ratio. When the level of GSSG, the oxidized form of GSH increased in the presence of persistently elevated ROS, then the redox state of cell get affected, and it may result in the development of diabetic complications. Measurement of intracellular GSH/GSSG ratio may provide valuable information about the redox status of the cell.

Ascorbic acid or "vitamin C" is a monosaccharide antioxidant found in both animals and plants. As it cannot be synthesized in humans and must be obtained from the diet. Most other animals are able to produce this compound in their bodies and do not require it in their diets. In cells, ascorbic acid is maintained in its reduced form by reaction with glutathione, which can be catalyzed by protein disulfide isomerase and glutaredoxins [74]. Ascorbic acid is a reducing agent capable of reduce and thereby neutralize ROS such as hydrogen peroxide [75].

Glutathione is a cysteine-containing peptide found in most forms of aerobic life. It is not required in the diet and is instead synthesized in cells from its constituent amino acids. Glutathione has antioxidant properties since the thiol group in its cysteine moiety is a reducing agent and can be reversibly oxidized and reduced. In cells, glutathione is maintained in the reduced form by the enzyme GR and in turn reduces other metabolites and enzyme systems as well as reacting directly with oxidants. Due to its high concentration and central role in maintaining the cell's redox state, glutathione is one of the most important cellular antioxidants. 
Vitamin E is the collective name for a set of eight related tocopherols and tocotrienols, which are fat-soluble vitamins with antioxidant properties [76]. It has been claimed that the $\alpha$-tocopherol form is the most important lipid-soluble antioxidant and that it protects membranes from oxidation by reacting with lipid radicals produced in the lipid peroxidation chain reaction [77]. This removes the free radical intermediates and prevents the propagation reaction from continuing. This reaction produces oxidized $\alpha$-tocopheroxyl radicals that can be recycled back to the active reduced form through reduction by other antioxidants, such as ascorbate, retinol, or ubiquinol [78].

The plasma levels of non-enzymatic antioxidants such as vitamin C, vitamin $\mathrm{E}$, reduced glutathione and ceruloplasmin and hepatic and renal GSH content were found to be increased on sinapic acid treatment. The observed improvement in the antioxidant status reflects the antioxidant property of sinapic acid. Free radicals damage contributes to the etiology of many chronic health problems such as cardiovascular and inflammatory diseases, cataract and cancer. Antioxidants prevent free radical induced tissue damage by preventing the formation of radicals, scavenging them, or by promoting their decomposition. Studies indicate that nutrition plays a crucial role in the prevention of chronic diseases, as most of them can be related to diet.

\section{CONCLUSION}

The results of this study evidenced that sinapic acid possess significant antioxidant property in addition to its antidiabetic activity. The improved antioxidant status and declined oxidative stress markers in plasma and tissues effectively illustrate the antioxidant potential of sinapic acid. The study also portrays the protective nature of sinapic acid against hyperglycemia-mediated oxidative stress in experimental Type 2 diabetes in rats.

\section{ACKNOWLEDGMENTS}

The Research Fellowship of the University Grant Commission (UGC), New Delhi, India, to the Mrs. R. Nithya in the form of UGC-BSR-RF is gratefully acknowledged.

\section{REFERENCES}

1. Tangvarasittichai S. Oxidative stress, insulin resistance, dyslipidemia and Type 2 diabetes mellitus. World J Diabetes 2015;6(3):456-80.

2. Johansen JS, Harris AK, Rychly DJ, Ergul A. Oxidative stress and the use of antioxidants in diabetes: Linking basic science to clinical practice. Cardiovasc Diabet 2005;4:5.

3. Robertson RP. Chronic oxidative stress as a central mechanism for glucose toxicity in pancreatic islet beta cells in diabetes. J Biol Chem 2004;279(41):42351-4.

4. Robertson RP, Harmon JS. Diabetes, glucose toxicity, and oxidative stress: A case of double jeopardy for the pancreatic islet beta-cell. Free Radic Biol Med 2006;41(2):177-84.

5. Prentki M, Joly E, El-Assaad W, Roduit R. Malonyl-CoA signalling, lipid partitioning, and glucolipotoxicity: Role in beta-cell adaptation and failure in the etiology of diabetes. Diabetes 2002:51 Suppl 3:S405-13.

6. Poitout V. Lipid partitioning in the pancreatic beta cell: Physiologic and pathophysiologic implications. Curr Opin Endocrinol Diabetes 2002;9:152-9.

7. Baynes JW. Role of oxidative stress in development of complications in diabetes. Diabetes 1991;40:405-12.

8. Halliwell B, Gutteridge J. Free Radicals in Biology and Medicine. $4^{\text {th }}$ ed. New York, NY, USA: Oxford University Press; 2007.

9. Gomes EC, Silva AN, de Oliveira MR. Oxidants, antioxidants, and the beneficial roles of exercise-induced production of reactive species. Oxid Med Cell Longev 2012;2012:756132.

10. Freitas M, Gomes A, Porto G, Fernandes E. Nickel induces oxidative burst, NF- $\kappa \mathrm{B}$ activation and interleukin- 8 production in human neutrophils. J Biol Inorg Chem 2010;15(8):1275-83.

11. Thannickal VJ, Fanburg BL. Reactive oxygen species in cell signaling. Am J Physiol Lung Cell Mol Physiol 2000;279(6):L1005-28.

12. Sen CK. Antioxidant and redox regulation of cellular signaling: Introduction. Med Sci Sports Exerc 2001;33(3):368-70.

13. Szaleczky E, Prechl J, Fehér J, Somogyi A. Alterations in enzymatic antioxidant defence in diabetes mellitus - A rational approach. Postgrad
Med J 1999;75:13-7.

14. Nisha K, Deshwal RK. Antioxidants and their protective action against DNA damage. Int J Pharm Pharm Sci 2011;3:28-32.

15. Shivashankar M, Mani D. A brief overview of diabetes. Int J Pharm Pharm Sci 2011;3:22-7.

16. Lenzen S. The mechanisms of alloxan- and streptozotocin-induced diabetes. Diabetologia 2008;51:216-26.

17. Ortiz RR, Sanchez SJ, Navarrete VG, Webster SP, Binnie M, Garcia JS. Antidiabetic and toxicological evaluations of naringeninin normoglycaemic and NIDDM rat models and its implications on extra-pancreatic glucose regulation. Diabetes Obes Metab 2008; 10:1097-104.

18. Veerapur VP, Prabhakar KR, Thippeswamy BS. Antidiabetic effect of Dodonaea viscosa (L). Lacq. aerial parts in high fructose-fed insulin resistant rats: A mechanism based study. Indian J Exp Biol 2010;48:800-10.

19. Shahidi F, Naczk M. Cereals, legumes and nuts. In: Phenolics in Food and Nutraceuticals. Boca Raton: CRC Press; 2004. p. 17-166.

20. Andreasen MF, Landbo AK, Christensen LP, Hansen A, Meyer AS. Antioxidant effects of phenolic rye (Secale cereale L.) extracts, monomeric hydroxycinnamates and ferulic acid dehydrodimers on human low-density lipoproteins. J Agric Food Chem 2001;49:4090-6.

21. Kikuzaki H, Hisamoto M, Hirose K, Akiyama K, Taniguchi $H$. Antioxidant properties of ferulic acid and its related compounds. J Agric Food Chem 2002;50:2161-8.

22. Yun KJ, Koh DJ, Kim SH, Park SJ, Ryu JH, Kim DG, et al. Antiinflammatory effects of sinapic acid through the suppression of inducible nitric oxide synthase, cyclooxygase 2 , and proinflammatory cytokine expressions via nuclear factor-kB inactivation. J Agric Food Chem 2008;56:10265-72.

23. Yoon BH, Jung JW, Lee JJ, Cho YW, Jang CG, Jin C, et al. Anxiolyticlike effects of sinapic acid in mice. Life Sci 2007;81:234-40.

24. Zou Y, Kim AR, Kim JE, Choi JS, Chung HY. Peroxynitrite scavenging activity of sinapic acid (3, 5-dimethoxy- 4-hydroxycinnamic acid) isolated from Brassica juncea. J Agric Food Chem 2002;50:5884-90.

25. Kim DH, Yoon BH, Jung WY, Kim JM, Park SJ, Park DH, et al. Sinapic acid attenuates kainic acid-induced hippocampalneuronal damage in mice. Neuropharmacology 2010;1:1-11.

26. Kanchana G, Shyni WJ, Rajadurai M, Periasamy R. Evaluation of antihyperglycemic effect of sinapic acid in normal and streptozotocininduced diabetes in albino rats, Global J Pharmacol 2011;5:33-9.

27. Bountagkidou OG, Ordoudi SA, Tsimidou MZ. Structure-antioxidant activity relationship study of natural hydroxybenzaldehydes using in vitro assays. Food Res Int 2010;43(8):2014-9.

28. Trnková L, Boušová I, Ryšánková L, Vrabcová P, Dršata J. Antioxidants and environmental stress: Spectroscopic study on stability of natural compounds and their interaction with a molecule of protein in an in vitro model. Proc Ecopole 2009;3(1):27-34.

29. Trnková L, Boušová I, Kubicek V, Dršata J. Binding of naturally occurring hydroxycinnamic acids to bovine serum albumin. Nat Sci 2010;2:563-70.

30. Kern SM, Bennett RN, Mellon FA, Kroon PA, Garcia-Conesa MT. Absorption of hydroxycinnamates in humans after high-bran cereal consumption. J Agric Food Chem 2003;51(20):6050-5.

31. Ader P, Grenacher B, Langguth P, Scharrer E, Wolffram S. Cinnamate uptake by rat small intestine: Transport kinetics and transepithelial transfer. Exp Physiol 1996;81(6):943-55.

32. Zhang K, Zuo Y. GC-MS determination of flavonoids and phenolic and benzoic acids in human plasma after consumption of cranberry juice. J Agric Food Chem 2004;52(2):222-7.

33. Griffiths LA. Metabolism of sinapic acid and related compoundsin the rat. Biochem J 1969;113(4):603-9.

34. Srinivasan K, Viswanad B, Asrat L, Kaul CL, Ramarao P. Combination of high-fat diet-fed and low-dose streptozotocin-treated rat: A model for Type 2 diabetes and pharmacological screening. Pharmacol Res 2005;52:313-20.

35. Brand-Williams W, Cuvelier ME, Berset C. Use of a free-radical method to evaluate antioxidant activity. Food Sci Technol Leb 1995;28:25-30.

36. Re R, Pellegrini N, Proteggente A, Pannala A, Yang M, Rice-Evans C. Antioxidant activity applying an improved ABTS radical cation decolorization assay. Free Radic Biol Med 1999;26:1231-7.

37. Fontana M, Mosca L, Rosei MA. Interaction of enkephalines with oxyradicals. Biochem Pharmacol 2001;61:1253-7.

38. Marcocci L, Maguire JJ, Droylefaix MT, Packer L. The nitric oxidescavenging properties of Ginkgo biloba extract EGb 761. Biochem Biophys Res Commun 1994;201:748-55.

39. Yagi K. Simple fluorimetric assay for lipid peroxides in blood plasma. 
Biochem Med 1976;15(2):212-5.

40. Ohkawa H, Ohishi N, Yagi K. Assay for lipid peroxides in animal tissues by thiobarbituric acid reaction. Anal Biochem 1979;95(2):351-8.

41. Jiang ZY, Hunt JV, Wolff SD. Ferrous ion oxidation in the presence of xylenol orange for detection of lipid hydroperoxide in low density lipoprotein. Anal Biochem 1992;202:384-9.

42. Misra HP, Fridovich I. The role of superoxide anion in the auto oxidation of epinephrine and a simple assay of superoxide dismutase. J Biol Chem 1972;24 (10):3170-5.

43. Takahara S, Hamilton BH, Nell JV, Kobra TY, Ogura Y, Nishimura ET. Hypocatalasemia, a new genetic carrier state. J Clin Invest 1960;39:610-9.

44. Rotruck JT, Pope AL, Gasther HE, Swanson AB, Hafeman DG, Hoekstra WG. Selenium biochemical role as a component of glutathione peroxidase. Science 1973;179(4073):588-90.

45. Habig WH, Pabst MJ, Jakoby WB. Glutathione S-transferase. The first enzymatic step in mercapturic acid formation. J Biol Chem 1974;249(22):7130-9.

46. Carlberg I, Mannervik B. Purification and characterization of the flavoenzyme glutathione reductase from rat liver. J Biol Chem 1975;250(14):5475-80

47. Omaye ST, Turnbull JD, Sauberlich HE. Selected methods for the determination of ascorbic acid in animal cells, tissues and fluids. Methods Enzymol 1979;62:3-11.

48. Desai ID. Vitamin E analysis methods for animal tissues. Methods Enzymol 1984;105:138-47.

49. Ravin HA. Improved colorimetric assay of ceruloplasmin. J Lab Clin Med 1961;58:161-8.

50. Sedlak J, Lindsay RH. Estimation of total, protein bound and nonprotein sulfhydryl groups in tissue with Ellmans reagent. Anal Biochem 1968;25(1):293-305.

51. Liu RH. Health benefits of fruit and vegetables are from additive and synergistic combinations of phytochemicals. Am J Clin Nutr 2003;78:517-20.

52. Kang HS, Kim KR, Jun EM, Park SH, Lee TS, Suh JW, et al. Cyathuscavins A, B, and C, new free radical scavengers with DNA protection activity from the Basidiomycete Cyathusstercoreus. Bioorg Med Chem Lett 2008;18:4047-50.

53. Lü JM, Lin PH, Yao Q, Chen C. Chemical and molecular mechanisms of antioxidants: Experimental approaches and model systems. J Cell Mol Med 2010;14:840-60.

54. Huy LA, He H, Huy CP. Free radicals, antioxidants in disease and health. Int J Biomed Sci 2008;4(2):89-96.

55. Shibuki K, Okada D. Endogenous nitric oxide release required for longterm synaptic depression in the cerebellum. Nature 1991;349:326-8.

56. Bredt DS, Snyder SH. Nitric oxide a physiologic messenger molecule. Annu Rev Biochem 1994;63:175-95.

57. Moncada S, Palmer RM, Higgs EA. Nitric oxide: Physiology, pathophysiology, and pharmacology. Pharmacol Rev 1991;43:109-42.

58. Nenadis N, Tsimidou M. Observations on the estimation of scavenging activity of phenolic compounds using rapid 1,1-diphenyl-2- picrylhydrazyl (DPPH') tests. J Am Oil Chem Soc 2002;79:1191-5.

59. Hotta H, Nagano S, Ueda M, Tsujino Y, Koyama J, Osakai T. Higher radical scavenging activities of polyphenolic antioxidants can be ascribed to chemical reactions following their oxidation. Biochim Biophys Acta 2002;1572:123-32.

60. Jalaludeen AM, Pari L. Studies on the antioxidant and free radicalscavenging effect of sinapic acid: An in vivo and in vitro model. J Pharm Sci Res 2001:3(9);1447-55.

61. Masek A, Chrzescijanska E, Latos M, Zaborski M. Antioxidant potential of hydroxycinnamic acids in advanced oxidation processes. Int J Electrochem Sci 2016;11:8848-60.

62. Ellingsen I, Hjerkinn E, Seljeflot I, Arnesen H, Tonstad S. Consumption of fruit and berries is inversely associated with carotid atherosclerosis in elderly men. Brit J Nutr 2008;99:674-81.

63. Pandey KB, Rizvi SI. Plant polyphenols as dietary antioxidants in human health and disease. Oxid Med Cell Longev 2009;2(5):270-8.

64. Martin KR, Appel CL. Polyphenols as dietary supplements: A doubleedged sword. Nutr Diet Suppl 2010;2:1-12.

65. Sies H. Oxidative stress: Oxidants and antioxidants. Exp Physiol 1997;82:291-5.

66. Magnenat JL, Garganoam M, Cao J. The nature of antioxidant defense mechanisms: A lesson from transgenic studies. Environ Health Perspect 1998;106:1219-28.

67. Zelko I, Mariani T, Folz R. Superoxide dismutase multigene family: A comparison of the CuZn-SOD (SOD1), Mn-SOD (SOD2), and ECSOD (SOD3) gene structures, evolution, and expression. Free Radic Biol Med 2002;33:337-49.

68. Johnson F, Giulivi C. Superoxide dismutases and their impact upon human health. Mol Aspects Med 2005;26:340-52.

69. Chelikani P, Fita I, Loewen PC. Diversity of structures and properties among catalases. Cell Mol Life Sci 2004;61:192-208.

70. Gaetani G, Ferraris A, Rolfo M, Mangerini R, Arena S, Kirkman H. Predominant role of catalase in the disposal of hydrogen peroxide within human erythrocytes. Blood 1996;87:1595-9.

71. Meister A, Anderson M. Glutathione. Annu Rev Biochem 1983;52:711-60

72. Brigelius-Flohe R. Tissue-specific functions of individual glutathione peroxidases. Free Radic Biol Med 1999;27:951-65.

73. Hayes J, Flanagan J, Jowsey I. Glutathione transferases. Annu Rev Pharmacol Toxicol 2005;45:51-88.

74. Smirnoff N. L-ascorbic acid biosynthesis. Vitam Horm 2001;61:241-66.

75. Padayatty S, Katz A, Wang Y, Eck P, Kwon O, Lee J, et al. Vitamin C as an antioxidant: Evaluation of its role in disease prevention. J Am Coll Nutr 2003;22:18-35.

76. Herrera E, Barbas C. Vitamin E: Action, metabolism and perspectives. J Physiol Biochem 2001;57:43-56.

77. Traber MG, Atkinson J. Vitamin E, antioxidant and nothing more. Free Radic Biol Med 2007;43:4-15.

78. Wang X, Quinn P. Vitamin E and its function in membranes. Prog Lipid Res 1999;38:309-36. 